\title{
PEROXIDAÇÃO LIPÍDICA E ETANOL: PAPEL DA GLUTATIONA REDUZIDA E DA VITAMINA E
}

\author{
LIPID PEROXIDATION AND ETHANOL: ROLE OF VITAMIN-E AND GLUTATHIONE
}

Alceu Afonso Jordão Júnior'; Paula Garcia Chiarello'; Mônica S.

Meirelles Bernardes ${ }^{2} \&$ Helio Vannucchi ${ }^{3}$

\begin{abstract}
'Doutorandos em Ciência dos Alimentos, Área de Nutrição Experimental da Faculdade de Ciências Farmacêuticas da Universidade de São Paulo; ${ }^{2}$ Especialista em Laboratório; ${ }^{3}$ Docente - Divisão de Nutrição Clínica do Departamento de Clínica Médica da Faculdade de Medicina de Ribeirão Preto da Universidade de São Paulo.

CorRespondÊNCIA: Prof.Dr. Helio Vannucchi - Divisão de Nutrição Clínica do Departamento de Clínica Médica da Faculdade de Medicina de Ribeirão Preto da Universidade de São Paulo - Av. Bandeirantes 3900; CEP: 14049-900 - Ribeirão Preto - SP. Email: hvannucc@fmrp.usp.br
\end{abstract}

JORDÃO Jr AA et al. Peroxidação lipídica e etanol: papel da glutationa reduzida e da vitamna E. Medicina, Ribeirão Preto, 31: 434-449, jul./set. 1998.

RESUMO: A geração de radicais livres é um passo importante na patogênese da injúria hepática, associada à ingestão de etanol. A ingestão do etanol induz a um aumento na peroxidação lipídica por dois mecanismos, por uma maior produção de espécies reativas de oxigênio e/ou pela diminuição dos níveis dos antioxidantes endógenos. Esta revisão enfoca a geração de radicais livres, especialmente a nível microssomal, e o papel de dois antioxidantes nutricionais, a vitamina E e a glutationa.

UNITERMOS: Peroxidação de Lipídios. Álcool Etílico. Glutationa. Vitamina E. Radicais Livres.

\section{INTRODUÇÃO}

É grande o número de doenças em que se sugere o envolvimento dos radicais livres ou das espécies reativas de oxigênio. Questiona-se, na maioria dos casos, se estas espécies representam a causa ou meramente a consequiência destas doenças ${ }^{(1)}$. Radicais livres e espécies reativas de oxigênio podem contribuir para o aparecimento de doenças ou estarem presentes em situações de toxicidade, como, por exemplo, diante do consumo de etanol. Na Tabela I, estão exemplificadas algumas situações onde acredita-se existir o envolvimento dos radicais livres. Desde que o impacto biológico adverso dos radicais livres esteja estabelecido, existe, por conseqüência, a necessidade de bloquear ou atenuar os seus efeitos deletérios ${ }^{(2)}$.

\begin{tabular}{|ll|}
\hline $\begin{array}{l}\text { Tabela I - Algumas condições nutricionais associa- } \\
\text { das com dano oxidativo }\end{array}$ \\
\hline Câncer & $\frac{\text { Alcoolismo }}{\text { Dermatite }}$ \\
Pancreatite & $\begin{array}{l}\text { Consumo elevado de ácidos } \\
\text { graxos }\end{array}$ \\
Artrite & Hipertensão \\
Doenças Inflamatórias & Sobrecarga de Ferro \\
Aterosclerose & Deficiência de Selênio \\
Diabetes & Isquemia e Reperfusão \\
Doença Renal & Deficiência de Vitamina E \\
Envelhecimento & \\
\hline
\end{tabular}


Neste sentido, é essencial o conhecimento dos processos nos quais os radicais livres estão envolvidos, quais são as espécies químicas geradas e sua atuação no processo fisiopatológico. Partindo deste ponto, devemos conhecer os compostos que podem atuar como antioxidantes, qual a sua localização nos sistemas biológicos, como atuam interferindo nos efeitos deletérios dos radicais livres. Por fim, devemos saber em que concentrações estes antioxidantes atuam e como podemos obtê-los. Ampliando nosso conhecimento em relação às questões que envolvem os radicais livres e os antioxidantes, melhores serão as condições de estabelecermos estratégias de intervenção, atenuando os efeitos do estresse oxidativo, nos sistemas biológicos.

Os sistemas biológicos oferecem condições favoráveis para ocorrência de reações de caráter oxidativo, devido à existência de lipídios insaturados, nas membranas celulares, e pela abundância de reações oxidativas que ocorrem durante o metabolismo normal. A susceptibilidade de uma célula ou de um tecido ao estresse oxidativo depende de um grande número de fatores que incluem a disponibilidade de antioxidantes e a capacidade de inativação ou eliminação dos produtos oxidados formados.

$\mathrm{O}$ estresse oxidativo tem sido definido como um distúrbio no estado de equilíbrio, no sistema de pró-oxidantes e antioxidantes, nas células intactas. Esta definição implica no fato de que a célula deve ter um sistema onde exista um equilíbrio entre a produção e a eliminação de espécies reativas de oxigênio durante o metabolismo aeróbico, normal. Quando existe maior ocorrência de eventos oxidativos, o sistema pende para o lado pró-oxidativo, o que pode afetar os níveis de antioxidantes como a glutationa e a vitamina E, tendo, como resultado final, o dano oxidativo em lipídios, proteínas, carboidratos e ácidos nucléicos. A severidade deste processo pode levar à morte celular.

A eficácia do sistema antioxidante depende muito de qual o tipo de molécula é a geradora do estresse oxidativo e da localização intra ou extracelular dessa molécula. Como exemplo, temos que o dano à membrana celular pode ser mais eficazmente prevenido pela vitamina $E$, que reage com radicais peroxila e hidroxila, do que pelos carotenóides, que atuam reagindo com o oxigênio singleto.

Há mais de (trinta) 30 anos, Di Luzio et al. propuseram que o estresse oxidativo era um dos componentes envolvidos na patogênese da doença hepática alcoólica $^{(3,4)}$. Células parenquimais e não parenquimais têm sido identificadas como fontes geradoras de radicais livres, devido à ação do etanol. Espécies reativas de oxigênio como o $\mathrm{O}_{2}^{\cdot}, \mathrm{H}_{2} \mathrm{O}_{2}$ e $\mathrm{OH}^{\bullet}$ são produzidas por estas células hepáticas, como uma consequiência da oxidação do etanol. O citocromo P4502E1, a NADPH oxidase e a NADPH citocromo P450 redutase parecem estar particularmente envolvidos como fonte de radicais livres, devido à inducibilidade destas enzimas, depois do consumo do etanol.

\section{RADICAIS LIVRES}

O que é um radical livre? Os átomos contêm um núcleo e os seus elétrons se distribuem ao redor do núcleo, usualmemente em pares. O radical livre é um átomo ou molécula que contém um ou mais elétrons não pareados. A presença deste elétron não pareado altera a reatividade química dos átomos ou moléculas, tornando-os mais reativos que as espécies não radicalares (com os elétrons pareados). O radical hidrogênio $\left(\mathrm{H}^{*}\right)$, que contém um (1) protón e um (1) elétron é o mais simples de todos os radicais. As reações em cadeia dos radicais livres são, então, iniciadas pela remoção (abstração) do $\left(\mathrm{H}^{*}\right)$ de outras moléculas, como, por exemplo, durante a peroxidação lipídica ${ }^{(5,6)}$.

Um radical livre é capaz de existir independentemente. Apresentam, em geral, uma grande instabilidade, têm uma vida muito curta e reagem rapidamente com diversos compostos e podem atacar alvos celulares $^{(5)}$. Os tipos de reação dos radicais livres podem levar à formação de complexos com proteínas, glicoproteínas, purinas e pirimidinas, formação de produtos de oxidação de tióis, peróxidos lipídicos, polímeros, epóxidos, endoperóxidos e produtos de cissão, como alquenais e hidroalquenais, que são citotóxicos. A oxidação de tióis, a ligação covalente de alquenais com proteínas e a modificação das glicoproteínas podem afetar a atividade enzimática ${ }^{(7)}$. Os processos de transcrição e de tradução podem ser impedidos ou modificados, em função de lesões no DNA, induzidas pelos radicais livres ${ }^{(2)}$. O termo espécies reativas de oxigênio é um coletivo que inclui não somente radicais de oxigênio como o radical superóxido $\left(\mathrm{O}_{2}^{-}\right)$ou hidroxila $\left(\mathrm{OH}^{\bullet}\right)$, mas, também, alguns derivados não radicalares, como o peróxido de hidrogênio $\left(\mathrm{H}_{2} \mathrm{O}_{2}\right)$ e o ácido hipocloroso $(\mathrm{HOCL})^{(8)}$, conforme demonstrado na Tabela II.

A natureza autocatalítica das reações com radicais livres é o fator mais importante na deterioração oxidativa de substratos orgânicos. Durante o estágio de propagação, um único radical pode produzir radicais ad infinitum, com somente a concentração de oxigênio e o reactante ditando o limite da reação. 


\begin{tabular}{|c|c|c|}
\hline Espéciє & Reativa de Oxigênio $N$ & Meia-vida (segundos) \\
\hline $\mathrm{HO}^{\circ}$ & Radical Hidroxila & $10^{-9}$ \\
\hline $\mathrm{HOO}^{\circ}$ & Radical Hidroperoxila & $10^{-8}$ \\
\hline $\mathrm{RO}^{\circ}$ & Radical Alcoxila & $10^{-6}$ \\
\hline $\mathrm{ROO}^{\circ}$ & Radical Peroxila & 7 \\
\hline ONOO• & Peroxinitrito & $0,05-1$ \\
\hline $\mathrm{H}_{2} \mathrm{O}_{2}$ & Peróxido de Hidrogênio & variável \\
\hline $\mathrm{O}_{2}^{-}$ & Radical Superóxido & variável \\
\hline${ }^{1} \mathrm{O}_{2}$ & Oxigênio Singleto & $10^{-5}$ \\
\hline NO & Radical Oxido Nítrico & $1-10$ \\
\hline $\mathrm{HOCL}$ & Ácido Hipocloroso & Estável \\
\hline
\end{tabular}

O oxigênio atmosférico, embora sendo um radical, não é reativo com moléculas biológicas, pois seus dois orbitais eletrônicos têm o mesmo estado em relação ao "spin". Entretanto, o oxigênio molecular pode ser reduzido a água. Os passos intermediários dessa redução são a formação do ânion superóxido, peróxido de hidrogênio e do radical hidroxila, que são correspondentes aos passos de uma redução por um, dois ou três elétrons, respectivamente.

Destas espécies formadas, o radical hidroxila é o que tem vida mais curta, reagindo praticamente no seu sítio de geração ${ }^{(9)}$.

$$
\mathrm{O}_{2}+\mathrm{e}^{-} \rightarrow \mathrm{O}_{2}^{-}
$$

Oxigênio molecular mais elétron resulta em radical superóxido

$$
\begin{aligned}
& \text { SOD } \\
& \mathrm{O}_{2}^{-}+\mathrm{O}_{2}^{-}+2 \mathrm{H}^{+} \rightarrow \mathrm{H}_{2} \mathrm{O}_{2}+\mathrm{O}_{2}
\end{aligned}
$$

Dismutação pelo superóxido dismutase, formando peróxido de hidrogênio

$$
\mathrm{H}_{2} \mathrm{O}_{2}+\mathrm{O}_{2}^{-}+\mathrm{Fe}^{++} \rightarrow \mathrm{OH}^{-}+\mathrm{OH}^{\bullet}+\mathrm{O}_{2}+\mathrm{Fe}^{+++}
$$

Presença de ferro, formando o radical hidroxila (reação de Fenton).

O radical hidroxila pode iniciar a peroxidação lipídica, abstraindo um hidrogênio da cadeia de ácidos graxos, poliinsaturados ${ }^{(10)}$.

\section{ANTIOXIDANTES}

Por definição, uma substância antioxidante é aquela capaz de inibir a oxidação ou, então, qualquer substância que, mesmo presente em baixa concentração, comparada ao seu substrato oxidável, diminui ou inibe a oxidação daquele substrato. Do ponto de vista biológico, podemos definir antioxidantes como aqueles compostos que protegem os sistemas biológicos contra os efeitos deletérios dos processos ou das reações que levam à oxidação de macromoléculas ou estruturas celulares. Isto implica que os diferentes antioxidantes podem atuar em níveis e com modo de ação distintos. Os antioxidantes podem, teoricamente, prolongar a fase de iniciação ou então inibir a fase de propagação, mas não podem previnir completamente a oxidação. Os antioxidantes podem ser classificados, didaticamente, em duas categorias, o sistema primário, que são os inibidores preventivos, que retardam a fase de iniciação, impedindo a geração de espécies reativas ou seqüestram estas espécies, impedindo sua interação com os alvos celulares, e o secundário. $\mathrm{O}$ sistema secundário consiste nos bloqueadores da etapa de propagação da cadeia radicalar (chain breaking), que, efetivamente, removem radicais intermediários, como o radical peroxila ou alcoxila. Os inibidores preventivos podem induzir a decomposição de hidroperóxidos para produtos inativos, exemplos são os tióis, sulfetos, catalases, peroxidases e as glutationas peroxidase e transferase. A superóxido dismutase (SOD) atua como um inibidor preventivo, reduzindo o ânion superóxido ao peróxido de hidrogênio. Os supressores do oxigênio singleto, como o $\beta$-caroteno e a vitamina $\mathrm{E}$, assim como os agentes quelantes, como peptídeos, ácidos orgânicos e certos fosfatos orgânicos ou inorgânicos, podem também ser considerados como antioxidantes preventivos $^{(2)}$. Na Tabela III, são exemplificados alguns compostos antioxidantes.

Os antioxidantes que bloqueiam a propagação da cadeia radicalar (chain breaking) interrompem a seqüência de auto-oxidação em cadeia, reagindo com os radicais livres, para produzirem produtos estáveis. Um inibidor da propagação em cadeia é rapidamente modificado a um produto inativo ou a um produto primário com uma atividade antioxidante residual. Podemos, ainda, considerar um terceiro sistema de defesa antioxidante que seriam os sistemas de reparo do DNA, as proteases e as fosfolipases, que removem as lesões oxidativas do DNA, proteínas e lipídios, respectivamente ${ }^{(1)}$. 
Tabela III - Componentes do sistema de proteção antioxidante

Antioxidantes não enzimáticos

Glutationa

Ubiquinona (Coenzima Q)

Ácido úrico

Bilirrubina

$\mathrm{NADPH}$ e NADH

Flavonóides

Vitamina C

Vitamina $\mathrm{E}$

Betacaroteno

Licopeno

Proteínas ligadoras de metais

Ceruloplasmina (cobre)

Metalotioneína (cobre)

Albumina (cobre)

Transferrina (ferro)

Mioglobina (ferro)

Antioxidantes enzimáticos

Superóxido Dismutase (SOD)

Catalase

Glutationa Peroxidase (GPx)

Quanto ao consumo de antioxidantes no plasma, a ordem teórica de preferência no consumo de antioxidantes, no processo de peroxidação lipídica, é a seguinte: vitamina $\mathrm{C}=$ tióis $(\mathrm{GSH})>$ bilirrubina > ácido úrico > vitamina $\mathrm{E}^{(11)}$. Desta maneira, nesta revisão, estamos avaliando dois antioxidantes que são consumidos em momentos diferentes, inicialmente a glutationa, que é mais hidrofílica e, finalmente, a vitamina E, substância hidrofóbica.

\section{ANTIOXIDANTE NUTRICIONAL: VITAMINA E}

A vitamina $\mathrm{E}$ foi descoberta em 1923, por Evans e Bishop, em estudos de fertilidade em ratos. Devido ao seu papel na fertilidade, a substância foi chamada de tocoferol, que, literalmente, significa a substância requerida para "assegurar nascimentos normais". Uma unidade internacional de vitamina E é o equivalente à atividade biológica de $1 \mathrm{mg}$ do acetato de dl- $\alpha$-tocoferol. A deficiência de vitamina E, em animais, provoca problemas no sistema reprodutivo, como abortos, nas fêmeas, e degeneração testicular, nos machos; provoca, também, distrofia muscular, cardiomiopatia, hemólise eritrocitária, necrose hepática e encefalomalácia entre outros efeitos indesejáveis. Já em 1947, alguns pesquisadores recomendavam o uso de vitamina E em doses que iam de dez (10) a cinqüenta (50) vezes a recomendação normal para humanos, principalmente no sentido de tratamento de várias doenças cardiovasculares ${ }^{(12)}$.

A vitamina $\mathrm{E}$ dietética é absorvida sob a forma não esterificada no intestino delgado, incorporada a quilomícrons e secretada na circulação linfática intestinal. A enzima lipase, lipoprotéica hidrolisa os triacilgliceróis nos quilomícrons e promove a formação de remanescentes de quilomícrons, que são captados pelo fígado via receptor específico para a apolipoproteína-E, localizado nas células parenquimais. A vitamina E é secretada pelas células parenquimais hepáticas, em associação com as lipoproteínas de muito baixa densidade (VLDL). Alguma vitamina E, associada a quilomícrons e VLDL, é, provavelmente, transferida às celulas periféricas e às lipoproteínas de alta densidade (HDL) durante o processo de lipólise. No metabolismo da VLDL, uma parte da vitamina se associa à LDL e segue os mecanismos de captação de LDL, tanto nas células parenquimais hepáticas quanto nas células periféricas ${ }^{(13,14)}$.

Os tocoferóis são antioxidantes fenólicos, num grupo composto de quatro diferentes isômeros, que se diferenciam pelo número e posição do grupo metila, ligado ao anel fenólico ${ }^{(15)}$. Os isômeros do tocoferol também contêm uma cadeia lateral fítica, que pode ser saturada, no caso do tocoferóis, ou insaturada, no caso dos tocotrienóis, perfazendo, então, oito homólogos naturais da vitamina E, que diferem em sua estrutura e atividade biológica. Dentre todos os tocoferóis conhecidos, o $\alpha$-tocoferol tem sido considerado o biologicamente mais ativo, inclusive no que diz respeito a sua atividade como antioxidante, sendo o principal antioxidante lipossolúvel, nas membranas celulares ${ }^{(16)}$. O fato de ser lipossolúvel confere ao $\alpha$-tocoferol propriedade de se acumular no interior das membranas e de ser transportado pelas lipoproteínas, especialmente pela lipoproteína de baixa densidade (LDL). $\mathrm{O} \alpha$-tocoferol da dieta é armazenado em vários tecidos, especialmente no fígado, tecido adiposo e 
músculo. A excreção do $\alpha$-tocoferol metabolizado é pouco conhecida, podendo ocorrer pelas fezes, pela via biliar ou pela pele ${ }^{(15)}$. Em condições patológicas de estresse oxidativo muito intenso, como, por exemplo, em pacientes com AIDS, o $\alpha$-tocoferol pode ser excretado de modo significativo pela via urinária ${ }^{(17)}$.

A função oxidante da vitamina é, essencialmente, a captura de radicais peroxila e alcoxila, levando ao término da reação em cadeia da lipoperoxidação por formar um aduto não radicalar. Nesse processo, o $\alpha$-tocoferol atua, doando um átomo de hidrogênio para estes radicais, derivados da oxidação de ácidos graxos. $O$ radical peroxila, analogamente, oxida a vitamina $\mathrm{E}$ e produz o radical tocoferoxila, um radical estável, que não propaga a cadeia. Subsequientemente, o radical tocoferoxila é regenerado à vitamina E pelo ácido ascórbico, mas glutationa e ácido úrico também são agentes de regeneração no plasma. A completa oxidação do tocoferoxila gera o $\alpha$-tocoferolquinona, por meio de reação irreversível. O mecanismo eficiente de regeneração do $\alpha$-tocoferol permite pouca formação irreversível deste último radical. A explicação corrente é a de que, assim que o radical tocoferoxila é formado, o $\alpha$-tocoferol é imediatamente regenerado, sugerindo que os níveis plasmáticos e teciduais de vitamina E sejam repostos por um "pool" mantido na forma não oxidada ${ }^{(14)}$.

O conteúdo de vitamina E determina a susceptibilidade das membranas microssomais, da LDL, hepatócitos e órgãos, em resposta ao dano provocado pelos radicais hidroxila, alcoxila, peroxila, oxigênio singleto e por alguns complexos entre os metais e o oxigênio. Estes agentes radicalares não somente danificam os lipídios, mas produzem intermediários secundários, os hidroperóxidos lipídicos, que podem ser decompostos em radicais peroxila e alcoxila, levando a uma cadeia ininterrupta de reações de peroxidação lipídica. Os tocoferóis atuam, principalmente, na proteção aos lipídios contra os radicais peroxila ${ }^{(18)}$

A capacidade antioxidante do $\alpha$-tocoferol está associada a sua estrutura fenólica. A sua cadeia fítica contribui muito pouco na atividade antioxidante, entretanto a presença desta cadeia facilita a incorporação e retenção do $\alpha$-tocoferol nas biomembranas ${ }^{(15)}$. Sendo muito intenso o processo de lipoperoxidação, o $\alpha$-tocoferol da membrana poderia ser totalmente convertido no radical tocoferoxila, perdendo sua ação como antioxidante. Entretanto, o radical tocoferoxila é regenerado por substâncias, como a vitamina $\mathrm{C}$ e a ubiquinona, entre outras, sendo, novamente, reduzido a $\alpha$-tocoferol ${ }^{(19)}$. Outros efeitos fisiológicos do $\alpha$-tocoferol incluem a alteração da fluidez da membrana, o aumento da função imune, a redução da mortalidade pela isquemia do coração, juntamente com a agregação plaquetária e a formação de coágulos ${ }^{(14)}$.

$\mathrm{O} \alpha$-tocoferol atua como um sequiestrador de radicais livres, em elevadas pressões de oxigênio, enquanto o $\beta$-caroteno é mais efetivo em ambientes de baixa pressão. $\mathrm{O} \alpha$-tocoferol é um eficiente antioxidante seqüestrador, que impede a propagação da cadeia radicalar, sendo, então, regenerado, via ciclo enzimático ou por redução não enzimática. A análise pela cromatografia líquida, de alta eficiência e ressonância eletrônica, paramagnética indica que o $\alpha$-tocoferol derivado do radical $\alpha$-cromanoxil pode ser reduzido pelo ácido ascórbico, NADPH, NADH, enzimas microssomais ou mitocondriais, dependentes do succinato e pelo complexo reducional do ácido $\alpha$-lipóico/diidrolipóico ${ }^{(14)}$. A ubiquinona também está implicada na regeneração do $\alpha$-tocoferol e pode atuar como um antioxidante independentemente de sua ação regenerativa sobre o $\alpha$-tocoferol ${ }^{(20)}$.

Um dos produtos formados na utilização do $\alpha$-tocoferol, no processo de peroxidação lipídica, o $\alpha$-tocoferilquinona é considerado um excelente anticoagulante e pode ser o responsável pelos efeitos benéficos do $\alpha$-tocoferol na prevenção de enfartos do miocárdio e ataques cardíacos. Quando administrado em seres humanos, o $\alpha$-tocoferilquinona é transformado em $\alpha$-tocoferol ${ }^{(21)}$. A ingestão de $350 \mathrm{mg}$ de $\alpha$-tocoferol, em humanos, resulta na formação de $\alpha$-tocoferoxil hidroquinina, que é posteriormente reduzido pela ubiquinona ${ }^{(22)}$.

Os animais são incapazes de sintetizar o $\alpha$-tocoferol, sendo dependentes das fontes dietéticas, sendo as suas principais fontes dietéticas os óleos vegetais; outras fontes incluem ovos, fígado, cereais e legumes. Na Tabela IV, exemplifica-se uma dieta geral, contendo quantidades adequadas de vitamina $\mathrm{E}$.

\section{TOXICIDADE DA VITAMINA E}

A evidência que micronutrientes e antioxidantes dietéticos protegem contra o dano oxidativo a tecidos é muito extensa. Entretanto, muitas questões importantes devem ser respondidas antes da recomendação acerca da suplementação nutricional ou mesmo da fortificação alimentar. As principais questões são quanto à toxicidade, o potencial da substância em exacerbar um estado patológico pré-existente e sua 


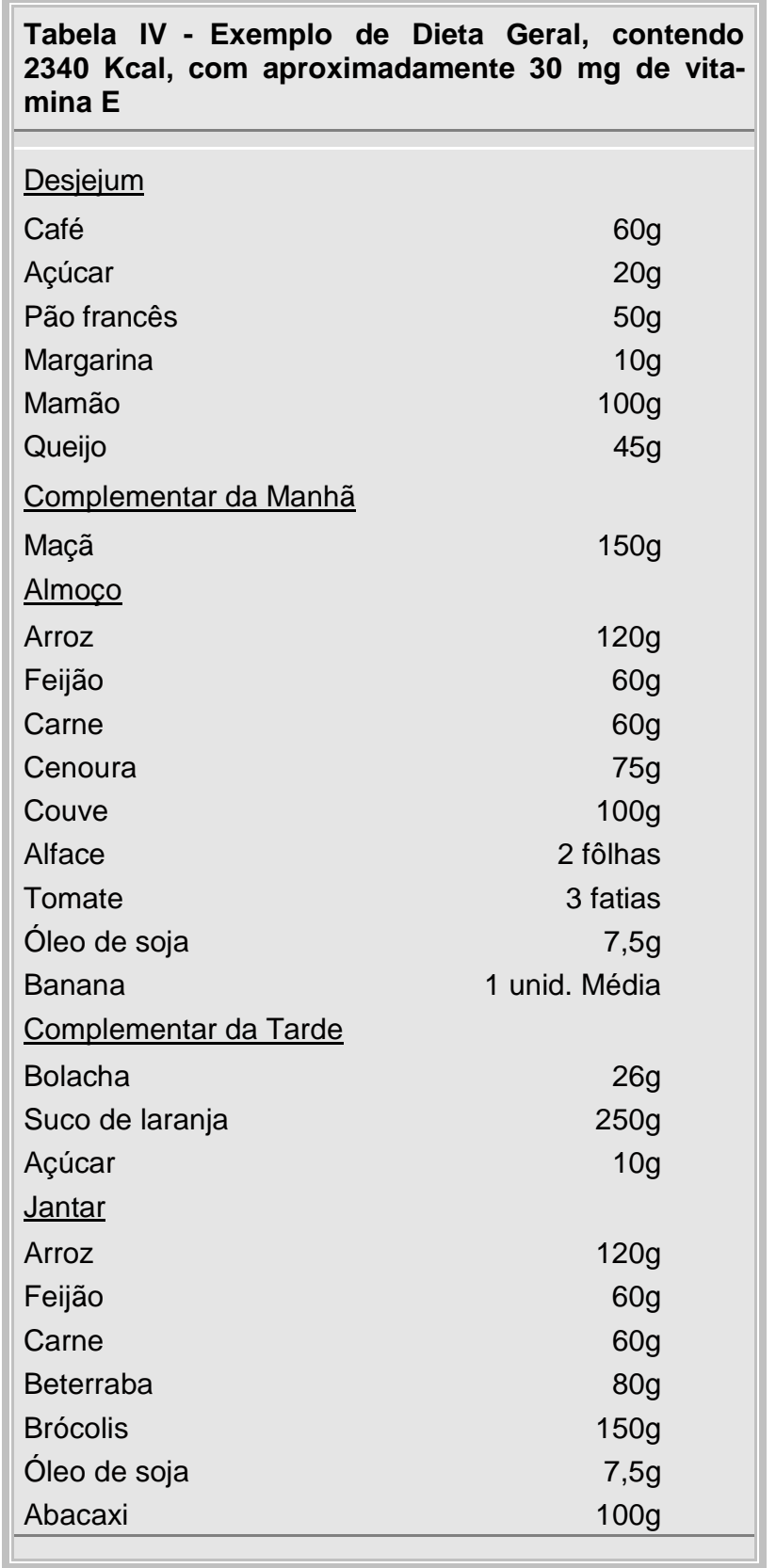

capacidade de ação antioxidante especifica sobre um órgão ou estado do organismo. Nesse sentido, parece não existirem grandes problemas em relação à toxicidade do $\alpha$-tocoferol, não sendo esta substância carcinogênica, mutagênica ou teratogênica, mesmo quando consumida em quantidades elevadas ${ }^{(23)}$. Entretanto, a administração do $\alpha$-tocoferol não é recomendada durante a terapia anticoagulante ou em pessoas portadoras de doença autoimune, pois pode precipitar acidentes hemorrágicos ou desencadear surtos autoimunes $^{(24)}$.

\section{ANTIOXIDANTE: GLUTATIONA}

A glutationa (GSH, L- $\gamma$-glutamil-L-cistenilglicina) é um tripeptídeo, contendo cisteína e é o tiol não protéico mais abundante nas células dos mamíferos. Concentrações baixas de GSH têm sido reportadas em algumas doenças, como a AIDS, e estão associadas a maior risco de estresse oxidativo e da ocorrência de infecções oportunísticas. Este decréscimo do GSH pode refletir o aumento na produção de antioxidantes, num grau que excederia a capacidade de detoxificação do $\mathrm{GSH}^{(25,26)}$. O núcleo do resíduo cistenilglicina da glutationa está envolvido na sua função como antioxidante, mais especificamente como um redutor intracelular, sendo capaz, por exemplo, de reagir com um elétron não pareado de um radical livre, formando um radical GS•, que produz, por dimerização, o GSSG (glutationa oxidada). O GSSG é, então, reduzido pela glutationa redutase, regenerando o GSH, num processo às custas do NADPH ${ }^{(27)}$. A glutationa redutase, que regenera o GSH tem o NADPH como substrato ${ }^{(27)}$. O fígado sintetiza o GSH, mas o GSH ingerido pode ser absorvido intacto, no intestino delgado, sendo transportado, aumentando o GSH plasmático.

A disponibilidade limitada do NADPH pode levar a aumento do GSSG e deixar as células mais sensíveis ao dano oxidativo ${ }^{(28)}$. O processo pelo qual a glutationa detoxifica hidroperóxidos é o seguinte:

$$
2 \mathrm{GSH}+\mathrm{ROOH}^{\bullet} \rightarrow \mathrm{GSSG}+\mathrm{ROH}+\mathrm{H}_{2} \mathrm{O}
$$

Outra atividade de proteção do GSH é na regeneração da vitamina E oxidada, no processo de detoxificação, sendo então:

$$
\begin{aligned}
\mathrm{R}^{\bullet}+\text { vit.E } & \rightarrow \mathrm{RH}+\text { vit } \mathrm{E}^{\bullet} \\
\text { vit. } \mathrm{E}^{\bullet}+\mathrm{GSH} & \rightarrow \text { vit } \mathrm{E}+\mathrm{GS} \bullet \\
2 \mathrm{GS}^{\bullet} & \rightarrow \mathrm{GSSG} \\
\mathrm{GSSG}+\mathrm{NADPH} & \rightarrow 2 \mathrm{GSH}+\mathrm{NADP}^{+}
\end{aligned}
$$

Portanto a glutationa (GSH) atua de maneira importante na proteção celular contra mudanças no quadro oxidativo e na defesa contra xenobióticos. Entre as funções do GSH, na proteção contra a peroxidação lipídica, lembramos que podem ocorrer três reações. Primeiro, o GSH é usado como substrato pela glutationa peroxidase, na eliminação de peróxidos. Segundo, o GSH reduz a forma oxidada da vitamina $\mathrm{C}$, que assim pode atuar, mantendo a vitamina $\mathrm{E}$ na sua forma reduzida e funcional. Finalmente, o GSH 
pode, através da glutationa-S-transferase, detoxificar aldeídos reativos (como o malondialdeído) que são gerados durante a peroxidação lipídica. Se, de fato, grande parte da ação do GSH é obtida pela indução de suas enzimas, é necessária a manutenção do nível de GSH para suportar a ação funcional destas enzi$\operatorname{mas}^{(29)}$. Variações nos níveis de glutationa afetam diretamente a síntese de proteínas e de DNA. Oxidação ou depleção do GSH pode diminuir a síntese protéica. O GSH pode ser perdido de modo irreversível em situações de estresse oxidativo muito intenso, permanecendo na forma oxidada e não sendo novamente reduzido $^{(30)}$.

\section{METABOLISMO DO ETANOL}

O etanol atinge todos os tecidos do organismo e afeta a maioria das funções vitais, por ser uma molécula pequena e solúvel tanto em meio aquoso como lipídico ${ }^{(31)}$. Após a ingestão de etanol, cerca de $20 \%$ do total é absorvido no estômago e o restante nas primeiras porções do intestino delgado. Somente de 2 a $10 \%$ do etanol absorvido é eliminado via rins e pulmões, o restante é oxidado, principalmente no fígado. Exceto pelo estômago, o metabolismo extra-hepático do etanol é muito pequeno ${ }^{(31)}$. A velocidade de absorção no estômago depende do tipo de bebida (no caso de humanos), da concentração de etanol, do pH do meio e do estado de vacuidade ou repleção do estômago. Em seres humanos, a ingestão de cerca de quarenta e cinco (45) gramas de etanol, tomados sob a forma de aguardente de cana, com o estômago vazio, resulta numa concentração, no sangue, que varia de 0,6 a 1,0 g/litro, após uma refeição esta concentração seria de 0,3 a $0,5 \mathrm{~g} /$ litro. No intestino delgado, a absorção é extremamente rápida, completa e independe da concentração de etanol ou da presença de alimentos. O etanol absorvido deverá ser oxidado, visto que o álcool não pode ser armazenado. Esta oxidação do álcool ocorre praticamente toda a nível hepático. A primeira fase da biotransformação do etanol compreende sua oxidação a acetaldeído. No hepatócito, esta transformação é realizada através de três caminhos distintos: via álcool desidrogenase, no citosol ou na parte solúvel da célula, via sistema microssomal de oxidação do etanol, localizada no retículo endoplasmático ou, então, via catalase, localizada nos peroxissomas, conforme é mostrado na Tabela V.

Cada um destes três processos produz metabólitos específicos e resultam na produção de acetaldeído, um produto também tóxico ${ }^{(31)}$. O processo através da álcool desidrogenase (ADH), localizada no citosol, é catalisado por esta enzima, tendo como cofator a nicotinamida adenina dinucleotídeo (NAD), que é convertida a sua forma reduzida, conforme a equação:

$$
\begin{gathered}
\text { ADH } \\
\mathrm{CH}_{3} \mathrm{CH}_{2} \mathrm{OH}+\mathrm{NAD}^{+} \rightarrow \mathrm{CH}_{3} \mathrm{CHO}+\mathrm{NADH}+\mathrm{H}^{+}
\end{gathered}
$$

$\mathrm{Na}$ oxidação do etanol pela álcool desidrogenase, ocorre a formação de um mol de NADH para cada mol de etanol oxidado. Já a aldeído desidrogenase é responsável pela oxidação do acetaldeído. Durante o metabolismo do etanol, o fígado permanece depletado de NAD, pois o NADH não é reoxidado em taxa suficiente para repor o $\mathrm{NAD}^{(32)}$.

A oxidação do etanol determina, assim, considerável produção de NADH e um aumento do $\mathrm{NAD}+\mathrm{H}^{+}$livre. A alteração deste sistema redox, com aumento da relação $\mathrm{NADH}_{2} / \mathrm{NAD}$, é responsável por alterações metabólicas, decorrentes do consumo do etanol, tais como o aumento da $\alpha$-glicerofosfato hepática e o estímulo à síntese de ácidos graxos com concomitante diminuição da oxidação normal dos ácidos graxos. Desta maneira, existe uma produção maior de triglicerídeos, criando-se condições para o apare-

\begin{tabular}{|c|c|c|c|}
\hline & $\mathrm{ADH}$ & MEOS & Catalase \\
\hline Localização & Citosol & Retículo Endoplasmático & Peroxissoma \\
\hline pH ótimo & - & $6,9-7,5$ & 5,5 \\
\hline Cofator & $\mathrm{NAD}+$ & NADPH & $\mathrm{H}_{2} \mathrm{O}_{2}$ \\
\hline
\end{tabular}
cimento da esteatose hepática. 
O tratamento crônico com etanol leva à oxidação do álcool pelo sistema microssomal, com participação primordial do citocromo $\mathrm{P} 4502 \mathrm{E} 1^{(32)}$.

A oxidação do etanol através do sistema de MEOS (microssomal ethanol oxidizing system) ocorre conforme a seguinte reação:

\section{MEOS}

$\mathrm{CH}_{3} \mathrm{CH}_{2} \mathrm{OH}+\mathrm{NADPH}+\mathrm{H}_{2}+\mathrm{O}_{2} \rightarrow \mathrm{CH}_{3} \mathrm{CHO}+\mathrm{NADP}^{+}+2 \mathrm{H}_{2} \mathrm{O}$

Este sistema é gradativamente estimulado pelo uso crônico do álcool. O envolvimento da catalase na oxidação do etanol é questionado, tendo por base a pequena produção do peróxido de hidrogênio, um pré-requisito para oxidação do etanol por esta via ${ }^{(32)}$. No processo oxidativo do etanol via catalase, ocorre, inicialmente, a oxidação do NADPH através da NADPH-oxidase, com a formação da água oxigenada, a qual, sob a influência da catalase, promove a oxidação do etanol. Neste processo, ocorrem as seguintes reações:

\section{NADP-oxidase}

$$
\begin{gathered}
\mathrm{NADPH}+\mathrm{H}^{+}+\mathrm{O}_{2} \rightarrow \mathrm{NADP}^{+}+\mathrm{H}_{2} \mathrm{O}_{2} \\
\mathrm{H}_{2} \mathrm{O}_{2}+\mathrm{CH}_{3} \mathrm{CH}_{2} \mathrm{OH} \rightarrow 2 \mathrm{H}_{2} \mathrm{O}+\mathrm{CH}_{3} \mathrm{CHO} \\
\text { Catalase }
\end{gathered}
$$

A biotransformação hepática peroxidativa do etanol é limitada pela produção endógena de água oxigenada. A produção fisiológica, normal, de água oxigenada é estimada como sendo de 3,6 mmol/hora/grama de fígado. Sob circunstâncias fisiológicas, o sistema catalase responde por menos de $2 \%$ da oxidação do etanol. Entretanto, o consumo de álcool induz a maior atividade de NADPH-oxidase, contribuindo para maior formação de água oxigenada, desta maneira, ampliando a participação deste sistema na oxidação do etanol. A segunda fase da oxidação do etanol ocorre a partir da formação do acetaldeído, com a formação de acetil-COA e acetato. A transformação do acetaldeído para acetato é praticamente irreversível. O acetaldeído pode inteirar com aminoácidos como lisina, serina e cisteína ${ }^{(32)}$. A oxidação do acetaldeído ocorre através da aldeídodesidrogenase, enzima que possui alta atividade mitocondrial. A formação de acetil-COA aumenta as chances de esteatose hepática. Além dos distúrbios da lipogênese, também ocorre uma maior redução do piruvato a lactato. Esta hiperlactacidemia contribui para acidose e ainda reduz a capacidade renal, quando a excreção de ácido úrico, provocando uma hiperuricemia secundária e uma hipoglicemia pós-alcóolica. Uma grande dose de etanol causa um aumento na taxa de metabolismo do etanol, coincidindo com um aumento de oxigênio no fígado. Este efeito é chamado de aumento rápido no metabolismo do etanol, sendo que este aumento, no fluxo de oxigênio, está ligado a um aumento na taxa de reoxidação do NADH e, conseqüentemente, na taxa de oxidação do etanol ${ }^{(32)}$. Um outro efeito de uma dose alta de etanol no fígado de ratos é o decréscimo do glicogênio hepático, depleção que depende da dose administrada de etanol. É possível que a depleção do glicogênio esteja associada ao aumento de fluxo de oxigênio no fígado, pelo aumento do NADH pela via do ácido citríco ou pela demanda de ATP necessário à repleção do glicogênio ${ }^{(32)}$. A enzima citocromo P4502E1 tem um papel central na detoxificação de xenobióticos, especialmente do etanol. Esta enzima tem como propriedade a ligação de elétrons ao oxigênio e no ciclo do NADH. Como consequiência, espécies reativas de oxigênio são formadas, incluindo os radicais hidroxila, que podem iniciar a peroxidação lipídica na membrana, gerando produtos tóxicos finais como o malondialdeído ${ }^{(33)}$. O CYP2E1 também tem um papel direto no dano hepático, podendo formar diretamente, através do etanol, o radical hidroxietila no retículo endoplasmático ${ }^{(32)}$. Tanto o acetaldeído como os radicais hidroxietila podem interagir com várias proteínas celulares, formando complexos que atuam como autoantígenos para iniciar a resposta imune ${ }^{(33)}$. A ativação das células de Kuppfer é um evento importante na iniciação da doença hepática alcoólica. Estas células podem ser ativadas por endotoxinas, tendo sua concentração de cálcio aumentada pela abertura dos canais de cálcio. A ativação destas células libera mediadores inflamatórios, incluindo citocinas e metabólitos lipídicos, assim como espécies reativas de oxigênio como o ânion superóxido ${ }^{(34)}$. Células de Kupffer também estão envolvidas no estado hipermetabólico com subseqüente hipoxia nas células parenquimais, efeito observado na doença hepática alcoólica. Desde que a hipoxia tem sido conhecida como promotora da formação de radicais livres é de se conceber que estes eventos podem levar à formação destas espécies reativas, durante o consumo de etanol ${ }^{(34)}$. Sabe-se que microssomos hepáticos, incubados com etanol, formam o radical hidroxietila $\left(\mathrm{CH}_{3} \mathrm{C} \cdot \mathrm{HOH}\right)$ via citocromo $\mathrm{P} 450$ e também existe a reação do etanol com o radical hidroxila $\left(\mathrm{OH}^{*}\right)$. O acetaldeído, formado via etanol, também é oxidado, formando o ânion superóxido $\left(\mathrm{O}_{2}^{-}\right)^{(35)}$. Alguns autores 
acreditam que os efeitos hepatotóxicos do etanol só seriam evidenciados em situações de desnutrição ${ }^{(36)}$, o que não parece ser confirmado, visto que animais, recebendo uma dieta nutricionalmente equilibrada, também sofrem os efeitos hepatotóxicos, provocados pela ingestão do etanol.

Muito se tem estudado sobre os efeitos da ingestão crônica de etanol no ser humano, visto que esta ingestão exerce um efeito tóxico, que se manifesta sobre o sistema nervoso central, fígado, pâncreas e coração, provocando alterações significativas no metabolismo intermediário de diversas substâncias ${ }^{(37)}$. Entre as alterações nutricionais decorrentes da ingestão de etanol, podemos citar aquelas verificadas no metabolismo da niacina ${ }^{(38)}$, do triptofano $^{(39)}$, do zinco $^{(40)}$, e da vitamina $\mathrm{B}_{6}$ em ratos ${ }^{(41)}$. Em relação ao metabolismo protéico, em alcoólatras, sabe-se que pacientes cirróticos apresentam alterações no metabolismo de aminoácidos no plasma ${ }^{(42)}$, e no líquido ascítico $^{(43)}$. No sentido de garantir o suprimento adequado de proteínas para alcoólatras, tem-se testado o uso de dietas enterais compostas de aminoácidos ${ }^{(44)} \mathrm{e}$ de fórmulas à base de leite de soja ${ }^{(45)}$.

Portanto, não existe dúvida quanto ao potencial tóxico do etanol, tanto no sentido da maior geração de espécies radicalares altamente reativas, como levando a alterações de alto significado nutricional.

\section{ETANOL E RADICAIS LIVRES}

Como foi citado, desde a década de sessenta (60), já se admitia a hipótese de que a ingestão de etanol poderia afetar a concentração de antioxidantes na célula hepática e que haveria um aumento na peroxidação lipídica em homogenatos de fígado, recebendo uma dose aguda de etanol ${ }^{(3,4)}$. Este aumento na peroxidação lipídica poderia ser prevenido pela adição, simultânea ao álcool, de antioxidantes. Estes resultados sugeriram que o etanol ou seus metabólitos poderiam atuar como pró-oxidantes ou reduzindo os níveis dos antioxidantes hepáticos ${ }^{(4)}$. Entretanto, outros autores não encontraram um aumento nas substâncias reativas ao ácido tiobarbitúrico (SRATB), que é um índice indireto da peroxidação lipídica, quando os ratos foram tratados tanto cronicamente ou de forma aguda com etanol ${ }^{(46,47)}$. Estes resultados discrepantes quanto à ocorrência da peroxidação lipídica hepática, após a administração do etanol, são, principalmente, devidos às diferentes condições experimentais utilizadas, assim como nas técnicas laboratoriais que quantificam a peroxidação lipídica. Estudos mais recentes, utilizando técnicas como quimioluminescência têm mostrado que a administração de etanol pode aumentar a peroxidação lipídica hepática em certas condições experimentais $^{(48,49,50)}$. Nesse sentido, acredita-se, principalmente, na indução do sistema do citocromo P450 microssomal assim como as enzimas xantina oxidase e aldeído oxidase, no citosol, como responsáveis pela geração de radicais livres pelo etanol. O etanol também pode levar a modificações no metabolismo do ferro, neste caso o ferro pode atuar como um fator pró-oxidante ${ }^{(51)}$. Sabe-se que a ingestão crônica de álcool em ratos tem aumentado a produção de espécies reativas de oxigênio em microssomas isolados, especialmente quanto à produção de superóxido $^{(52)}$, peróxido de hidrogênio ${ }^{(53)}$ e radicais hidroxila ${ }^{(54)}$. Estes radicais podem ser gerados pela NADPH-citocromo $\mathrm{P} 450$ redutase, uma flavoenzima que pode produzir superóxido, levando os radicais hidroxila $\left(\mathrm{OH}^{*}\right)$ para reação de Haber-Weiss, catalizada pelo ferro ${ }^{(51)}$. Mas a maior parte dos derivados de oxigênio, produzidos nos microssomos, ocorre pela indução do citocromo $\mathrm{P} 450$, mais especificamente sua isoenzima a CYP2E1, no sistema de oxidação microssomal do etanol. Esta isoenzima a citocromo P450 CYP2E1 pode ser induzida pelo etanol e outros álcoois ${ }^{(55)}$, acetona e várias outras substâncias ${ }^{(56)}$, com capacidade para gerar $\mathrm{O}_{2}^{-} \mathrm{e}_{2} \mathrm{O}_{2}$. A ingestão aguda de etanol leva a aumento significante na geração de radicais superóxidos nas mitocôndrias, favorecido pelo decréscimo da taxa NAD+/NADH ${ }^{(57,58)}$.

Nos estudos experimentais, o álcool deve ser administrado aos animais separado dos alimentos, o que é de fácil execução. $\mathrm{O}$ valor calórico do álcool é de 7,11 Kcal/grama e, em um milílitro de etanol, temos 0,798 de grama de etanol, oferecendo, então, $5,67 \mathrm{Kcal}^{\text {por }} \mathrm{ml}^{(59)}$; portanto deve-se levar em conta o potencial calórico do etanol.

Em ratos, foi administrado etanol de modo agudo na concentração cinco (5) gramas/kg de peso, numa solução com $50 \%$ de água, por via intragástrica, sendo medidas as SRATB e a alaninoaminotransferase (ALT) em períodos de 0, 2, 4, 8 e 24 horas após a administração do álcool. As SRATB aumentam nas duas (2) horas e depois voltam ao nível normal, a ALT sérica aumenta somente depois da queda das SRATB.

Esses resultados indicam que o aumento da peroxidação lipídica, após a administração aguda do etanol, é dependente do tempo e precede o dano 
hepatocelular ${ }^{(60)}$. Tais resultados fortalecem a hipótese de que os efeitos hepatotóxicos do etanol são devidos ao aumento na produção dos intermediários das espécies reativas de oxigênio. Um dos problemas associados com a identificação da peroxidação lipídica como mediadora da injúria aguda do etanol vem do fato de que o malondialdeído, principal componente das SRATB é rapidamente metabolizado. Desta maneira, as possíveis discrepâncias em relação à ocorrência do aumento na peroxidação lipídica depois da administração de etanol pode ser explicada, em parte, devido ao tempo em que o material biológico é coletado após a administração do álcool. A administração de $5 \mathrm{~g}$ de etanol/kg de peso para ratos por quatro (4) semanas não levou à formação de peróxidos lipídicos e nem alterou os níveis de antioxidantes enzimáticos e não enzimáticos. Nesse período de quatro (4) semanas pode ocorrer uma adaptação fisiológica dos animais à administração do álcool ${ }^{(61)}$.

\section{ETANOL E ANTIOXIDANTES}

Não existe um consenso sobre os efeitos do etanol nas concentrações de vitamina $\mathrm{E}$ e glutationa. $\mathrm{O}$ efeito protetor da vitamina $\mathrm{E}$ contra a injúria provocada pela participação de radicais livres em vários processos patológicos tem sido objetivo de vários trabalhos experimentais e epidemiológicos. Por ser constituinte essencial de membranas citoplasmáticas, um dos alvos preferencias de espécies reativas de oxigênio no desencadeamento de lipoperoxidação e também local de ataque de intermediários reativos provenientes do metabolismo do etanol, a vitamina $\mathrm{E}$ talvez possa desempenhar um papel protetor frente a uma dose aguda de etanol.

Segundo TYOPPONEN et al. ${ }^{(62)} \mathrm{o}$ tratamento crônico com etanol parece não afetar os níveis de vitamina $\mathrm{E}$, mas a deficiência da vitamina $\mathrm{E}$ tem sido considerada um potencializador dos efeitos hepatotóxicos do etanol. As enzimas álcool e aldeído desidrogenase têm a sua atividade hepática aumentada pela deficiência da vitamina $\mathrm{E}$, afetando, portanto, a taxa de eliminação do etanol. A deficiência da vitamina $\mathrm{E}$ pode ser compensada pelo aumento do GSH hepático $^{(62)}$. A administração crônica do etanol interfere negativamente no processo de regeneração hepática, após a hepatectomia parcial, sendo que a deficiência de vitamina E potencializa esses efeitos. Nesse sentido, parece que a deficiência da vitamina $\mathrm{E}$ inibe a síntese do $\mathrm{DNA}^{(63)}$. A administração de etanol por seis semanas levou a uma diminuição de $25 \%$ do $\alpha$-tocoferol, no fígado, especialmente nas células parenquimais, e levou, também, a uma diminuição de $55 \%$ no $\alpha$-tocoferol mitocondrial, quando comparado com o controle. Os níveis séricos de $\alpha$-tocoferol não mostraram diferença nos ratos recebendo etanol ${ }^{(13)}$. A administração de uma dieta deficiente em vitamina $\mathrm{E}$ para ratos, por cento e vinte (120) dias, foi a responsável pelo decréscimo do citocromo $\mathrm{P} 450$ hepático, por baixos níveis de vitamina $\mathrm{E}$ sérica, aliados a um aumento dos níveis do malondialdeído hepático ${ }^{(64)}$.

Outro grupo de autores acredita que apenas a ingestão crônica de etanol poderia levar a uma diminuição do $\alpha$-tocoferol hepático, não tendo a ingestão aguda os mesmos efeitos ${ }^{(13,65)}$. Entretanto, os efeitos da administração de etanol sobre a quantidade de $\alpha$-tocoferol hepático dependeriam da dose administrada, do tempo de administração do etanol e da quantidade de vitamina $\mathrm{E}$ adicionada à dieta destes animais. Já a deficiência de vitamina E pode potencializar a toxicidade do etanol no fígado ${ }^{(62)}$.

A produção de SRATB, induzida pelo t-butil hidroperóxido, em hepatócitos, foi suprimida pelo $\alpha$-tocoferol. Na ausência do $\alpha$-tocoferol, os níveis de tióis diminuiram em cerca de $40 \%$, já, com a adição da vitamina $\mathrm{E}$, a diminuição foi de $20 \%$. O tratamento com vitamina $\mathrm{E}$ também diminuiu o aparecimento de anormalidades morfológicas nos hepatócitos, resultantes do dano celular ${ }^{(66)}$.

O mecanismo de redução do $\alpha$-tocoferol hepático e plasmático, como efeito da administração do álcool, não é totalmente conhecido, mas acredita-se que possa ocorrer maior mobilização hepática e também aumento na conversão do $\alpha$-tocoferol para $\alpha$-tocoferilquinona. Nos ratos deficientes em vitamina $\mathrm{E}$, tem-se que a ingestão de etanol não diminuiria a concentração plasmática de $\alpha$-tocoferol, apenas o seu conteúdo hepático ${ }^{(67)}$.

A deficiência de vitamina E, no alcoolismo crônico humano, não tem sido bem caracterizada. Quando níveis séricos, baixos, de vitamina E são encontrados em alcoólatras têm-se colocado as possibilidades de insuficiência hepática, má-absorção de gorduras ou ingestão deficiente ${ }^{(68)}$. Em pacientes com pancreatite crônica, têm-se encontrado níveis baixos das vitaminas $\mathrm{E}$ e A e do selênio no plasma, associados a um decréscimo da glutationa peroxidase, plasmática, entretanto os níveis de SRATB não estão alterados nestes pacientes ${ }^{(69)}$, conforme mostrado na Tabela VI. 


\begin{tabular}{|lcc|}
$\begin{array}{l}\text { Tabela VI - Níveis } \\
\text { tiona peroxidase (GSH-Px) e SRATB em pacientes com pancreatite } \\
\text { crônica }{ }^{(69)}\end{array}$ & Pacientes $(\mathrm{n}=35)$ & Controle $(\mathrm{n}=14)$ \\
\hline \multicolumn{1}{|c|}{ Parâmetro } & $30 \pm 11$ & $49 \pm 12^{*}$ \\
\hline Vitamina A $(\mu \mathrm{g} / \mathrm{dl})$ & $8 \pm 5$ & $16 \pm 9^{*}$ \\
Vitamina E $(\mathrm{mg} / \mathrm{l})$ & $54 \pm 20$ & $87 \pm 11^{*}$ \\
Selênio $(\mu \mathrm{g} / \mathrm{l})$ & $903 \pm 313$ & $1326 \pm 168^{*}$ \\
GSH-Px $(\mathrm{unidades} / \mathrm{l})$ & $0,88 \pm 0,41$ & $0,87 \pm 0,08$ \\
SRATB $(\mu \mathrm{mol} / \mathrm{l})$ & & \\
\hline * $\mathrm{p}<0,05$ & & \\
\hline
\end{tabular}

necrose hepática ocorreram entre quinze (15) e vinte (20) horas após a administração da xenobiótico, sendo que somente na vigésima hora houve um decréscimo da vitamina E hepática. Quando se administrou um álcool alifático, o GSH decresceu significativamente em apenas quinze a trinta (15-30) minutos, a peroxidação lipídica foi verificada entre duas e quatro (2 e 4) horas após a administração do xenobiótico, e a vitamina $\mathrm{E}$ decaiu na quarta hora. Estudando-se os mesmos parâmetros, mas em animais deficientes em vitamina $\mathrm{E}$, ve-

O GSH é considerado o mais importante composto sulfidrila intracelular, sendo conhecido seu envolvimento num grande número de processos funcionais, celulares, principalmente quanto a sua participação em algumas reações de detoxificação. O GSH pode reagir diretamente com alguns compostos tóxicos, formando complexos ou, então, participando como substrato em reações de conjugação. Intoxicação crônica com etanol resulta num aumento na formação de peróxidos lipídicos, favorecendo o consumo de GSH e sua oxidação para GSSG pela glutationa peroxidase ${ }^{(70)}$. Sabe-se que o jejum pode reduzir em até $50 \%$ a quantidade de GSH hepático, e potencializar a necrose quando existe a administração de xenobióticos. Alguns autores acreditam que a suplementação de vitamina $E$ não é capaz de preservar a glutationa hepática, mesmo prevenindo a peroxidação lipídica ${ }^{(71)}$; nesse sentido, a depleção do GSH não estaria associada à toxicidade, quando existe uma quantidade adequada de vitamina $\mathrm{E}$, principalmente a nível hepático. Sob este ponto de vista, a extensão da peroxidação lipídica está mais relacionada à quantidade de $\alpha$-tocoferol do que ao $\mathrm{GSH}^{(72)}$. Num estudo, verificando a toxicidade aguda de vários xenobióticos, encontraram-se relações interessantes entre o metabolismo da vitamina E, glutationa, hepática e peroxidação lipídica. Administrando-se o bromobenzeno, percebeu-se um decréscimo muito rápido do GSH hepático, em cerca de três (3) horas, sendo a vitamina E reduzida em doze (12) horas e a peroxidação lipídica, assim como a necrose hepática, ocorreram após quinze (15) horas. Já a administração aguda do dietilmaleato induziu a uma queda dos níveis de GSH em apenas uma hora, mas a peroxidação lipídica e a rificou-se que o processo de peroxidação lipídica, da necrose hepática e o consumo de antioxidantes (vitamina $\mathrm{E}$ e GSH) estavam mais acelerados e mais intensos; já, em animais tratados com uma dieta suplementada em vitamina $\mathrm{E}$, houve uma prevenção quanto à ocorrência da peroxidação lipídica e da necrose hepática, mas esta suplementação não modificou a taxa de depleção do $\mathrm{GSH}^{(71)}$. Nesse experimento, a depleção do GSH foi associada à citotoxicidade, mesmo existindo uma quantidade adequada de $\alpha$-tocoferol. O decréscimo do GSH precederia o decréscimo da vitamina $\mathrm{E}$ e a ocorrência da peroxidação lipídica.

A relação entre a administração crônica do etanol e o metabolismo da glutationa não está estabelecida, existindo indicações de que os níveis de glutationa não são alterados ${ }^{(73)}$, podem decrescer ${ }^{(74)}$ ou mesmo aumentar frente à ingestão crônica de etanol ${ }^{(75)}$. Estas disparidades podem estar relacionadas à duranutricional. Além da diminuição hepática do GSH, tem sido relatada uma diminuição renal deste tripeptídeo após a ingestão crônica de etanol, sendo que os níveis de GSH no intestino, estômago e baço parecem não ser afetados pela ingestão do álcool ${ }^{(76)}$

Como foi citado, os níveis de glutationa (GSH) hepática podem sofrer um decréscimo quando existe a administração aguda de etanol. A formação de um complexo entre o acetaldeído, resultante da oxidação do etanol, e a glutationa pode representar um dos mecanismos desta diminuição ${ }^{(77)}$. A administração do próprio acetaldeído, para os animais, é capaz de diminuir os níveis de GSH e aumentar a concentração dos dienos conjugados a nível hepático ${ }^{(78)}$, conforme mostrado na Tabela VII. ção da exposição ao etanol, assim como à influência 


\begin{tabular}{|c|c|c|}
\hline Tratamento & GSH ( $\mu \mathrm{mol} / \mathrm{g} /$ fígado $)$ & $\begin{array}{l}\text { Dienos conjugados } \\
\text { (nmol/mg/proteína) }\end{array}$ \\
\hline Salina & $4,49 \pm 0,31$ & $81,3 \pm 11,9$ \\
\hline Acetaldeído $(0,3 \mathrm{~g} / \mathrm{Kg})$ & $3,34 \pm 0,13$ * & $128,6 \pm 13,9$ * \\
\hline Etanol (3 g/Kg) & $2,93 \pm 0,28$ * & $87,4 \pm 6,6$ \\
\hline Etanol (5 g/kg) & $2,04 \pm 0,15$ * & $159,3 \pm 6,9$ * \\
\hline
\end{tabular}

Quanto ao metabolismo das enzimas relacionadas ao GSH, a administração crônica de etanol aumenta a atividade das enzimas glutationa peroxidase e glutationa redutase em aproximadamente 45 e $15 \%$, respectivamente. A glutationa peroxidase aumentaria, como conseqüência de sua atividade em situações de peroxidação, já o aumento da glutationa redutase é um reflexo da maior demanda do GSH, com sua oxidação para GSSG $^{(82)}$. A ingestão aguda de etanol diminui os níveis dos grupos

A suplementação dietética com vitamina $\mathrm{E}$ ou vitamina $\mathrm{D}_{3}$ é capaz de elevar os níveis do GSH hepático ${ }^{(79)}$. $\mathrm{O}$ aumento na produção de $\mathrm{O}_{2}{ }^{-} \mathrm{e}_{2} \mathrm{O}_{2}$ acompanha a oxidação do etanol. Uma dieta contendo $5 \%$ de etanol, administrada por vinte e um (21) dias levou a um aumento do GSH hepático, principalmente quando os animais eram deficientes em vitamina E. O etanol também levou a uma diminuição do $\alpha$-tocoferol hepático, mas aumentou, de modo significativo, o $\alpha$-tocoferol plasmático ${ }^{(80)}$. Em ratos, recebendo uma dieta suplementada com mil e duzentas (1200) vezes o valor recomendado para vitamina $\mathrm{E}$ e etanol, por um mês, houve, de modo surpreendente, um aumento nas concentrações hepáticas de SRATB e ao $\alpha$-tocoferol, no grupo que recebeu etanol + vitamina $\mathrm{E}$, em comparação ao grupo que recebeu apenas vitamina E. A suplementação com vitamina E também não foi capaz de proteger contra os danos patológicos ao tecido hepático ${ }^{(81)}$, conforme mostrado na Tabela VIII. sulfidrila, ligados ou não a proteínas. Em relação aos tióis livres, como a glutationa, existe um decréscimo hepático que é dose dependente em relação à administração de etanol, sendo que dois (2) gramas de etanol/Kg peso do rato diminui o GSH hepático a $66,93 \%$ em relação ao controle. Já a administração do etanol a cinco (5) gramas $/ \mathrm{Kg}$ de peso do animal levou o GSH hepático a apenas 21,69\% dos níveis do controle. As duas quantidades aplicadas de etanol, de modo agudo, foram capazes de elevar as concentrações de malondialdeído no plasma, cérebro e fígado ${ }^{(83)}$.

\section{CONSIDERAÇÕES FINAIS}

\subsection{Estudos experimentais}

A presente revisão foi realizada no sentido de determinar os efeitos da administração do etanol sobre a peroxidação lipídica, e o possível papel protetor de antioxidantes, como a vitamina $\mathrm{E}$ e a glutationa. Tem-se, claramente, que o etanol atua no organismo de uma maneira pró-oxidativa, gerando espécies reativas de oxigênio. Postula-se, portanto, qual seria o

\begin{tabular}{|c|c|c|c|}
\hline Grupos & $\alpha$-tocoferol ( $\mu \mathrm{g} / \mathrm{g}$ fígado) & SRATB ( $\mu \mathrm{mol} / \mathrm{mg} /$ proteína) & Dano Patológico (score) \\
\hline Etanol & $2,3 \pm 1,5^{\mathrm{a}}$ & $512 \pm 46^{c}$ & $3,3 \pm 0,5^{b}$ \\
\hline Destrose + vit.E & $286 \pm 108^{b}$ & $75 \pm 15^{a}$ & $0,4 \pm 0,4^{a}$ \\
\hline Etanol + vit.E & $1749 \pm 481^{c}$ & $139 \pm 18^{b}$ & $3,4 \pm 0,8^{b}$ \\
\hline
\end{tabular}


papel de antioxidantes nutricionais frente a ingestão aguda ou crônica de etanol. Nesse sentido, verificamos, em alguns experimentos, que o etanol pode diminuir as concentrações hepáticas de vitamina $\mathrm{E}$ e de glutationa reduzida. Já a suplementação de vitamina tem-se mostrado efetiva em apenas algumas situações experimentais de administração de etanol, entretanto, não se tem comprovada a eficiência desta suplementação em humanos. Experimentos mostram que a modificação, tanto nos níveis da peroxidação lipídica como nos níveis de antioxidantes, depende, fundamentalmente, do tempo e pode explicar, pelo menos em parte, os resultados discrepantes em relação ao envolvimento de radicais livres e antioxidantes no metabolismo do etanol.

\subsection{Suplementação antioxidante em alcoólatras}

Quando tratamos de assunto ligado ao tema antioxidante e radicais livres, logo surge a questão dos suplementos antioxidantes. Seriam eles adequados ao consumo humano numa variedade de situações? O interesse crescente na aplicação de nutrientes antioxidantes, numa série de condições, incluindo aí a melhora geral da saúde e o retardo no processo de envelhecimento, tem atraído a atenção da população em geral, que deseja, em última análise, saber quais são os benefícios da ingestão de quantidades elevadas de suplementos antioxidantes. Infelizmente, a confusão, a falta de informação ou mesmo a informação enganosa levaram ao comércio de suplementos, negócio altamente rendoso para alguns, mas de pouco significado prático para o consumidor, pois estes suplemementos, vendidos como "fazedores de milagre", são indicados sem base científica, mas como a panáceia universal contra todos os males. Em 1993, a revista "Newsweek" revelou que sete (7) entre cada dez (10) norte-americanos consumiam suplementos, continua- da ou ocasionalmente, sendo que, no mercado norteamericano, neste período, existiam três mil e quatrocentos (3.400) diferentes tipos de suplementos minerais e vitamínicos, numa indústria que movimenta cerca de quatro (4) bilhões de dólares por ano ${ }^{(84)}$.

Muito se tem falado sobre a suplementação de vitamina $\mathrm{E}$ como mecanismo preventivo da peroxidação lipídica. Por exemplo, o enriquecimento da lipoproteína de alta densidade com $\alpha$-tocoferol estabiliza a produção de hidroperóxidos e diminui a formação de produtos secundários de oxidação, como as SRATB ${ }^{(85)}$. Entretanto, num estudo in vitro, a suplementação com vários antioxidantes não melhorou a defesa contra o estresse oxidativo ${ }^{(86)}$. Avaliando-se os efeitos da vitamina como antioxidante, em um estudo com lipoproteínas de baixa densidade (LDL), o $\alpha$-tocoferol mostrou uma atividade contrária ao esperado, agindo como substância pró-oxidante ${ }^{(87)}$. A suplementação diária com $500 \mathrm{mg}$ de vitamina $\mathrm{E}$, por um período de um ano, em alcoólatras crônicos, aumentou significativamente o nível plasmático de $\alpha$-tocoferol, mas não influenciou em parâmetros de função hepática, mortalidade ou tempo de permanência desses pacientes no hospital ${ }^{(88)}$. Devemos lembrar que, a nível experimental, a suplementação com mil e duzentas (1200) vezes a quantidade recomendada de vitamina $E$ não se mostrou efetiva ${ }^{(81)}$.

Tendo em vista estas informações, adotamos, como posição, o declarado pela "American Dietetic Association", que se manifestou em relação ao consumo de antioxidantes, afirmando que a melhor estratégia nutricional para promover a saúde e reduzir o risco de doenças crônicas é a obtenção dos nutrientes de uma grande variedade de alimentos. Suplementos vitamínicos e minerais só seriam apropriados quando bem aceitos pelo paciente e prescritos sob evidências científicas que comprovem sua eficácia e sua segurança ${ }^{(84)}$.

JORDÃO Jr AA et al. Lipid peroxidation and ethanol: role of vitamin-E and glutathione. Medicina, Ribeirão Preto, 31: 434-449, july/sept. 1998.

ABSTRACT: Free radical generation is a important step in the pathogenesis of ethanol associated liver injury. Administration of ethanol induces an increase in lipid peroxidation either by enhancing the production of oxygen reactive species and by decreasing levels of endogenous antioxidants. This review focuses the generation of free radical, specially at the microssomal levels and the role of two nutritional antioxidants: vitamin $\mathrm{E}$ and glutathione.

UNITERMS: Lipid Peroxidation. Alcohol, Ethyl. Glutathione. Vitamin E. Free Radicals. 


\section{REFERÊNCIAS BIBLIOGRÁFICAS}

1 - HALLIWELL B. Oxidants and human disease: some new concepts. FASEB J 1: 358-364, 1987.

2 - BONORDEN WR \& PARIZA MW. Antioxidant nutrients and protection from free radicals. In: Kotsonis FN et al. Nutritional Toxicology, Raven Press, New York, p. 19-48, 1994.

3 - DI LUZIO NR. Prevention of the acute ethanol-induced fatty liver by antioxidants. Physiologist 6:169-173, 1963.

4 - DI LUZIO NR. \& HARTMAN AD. Role of lipid peroxidation in the pathogenesis of ethanol-induced fatty liver. Fed Proc 26: 1436-1442, 1967.

5 - HALLIWELL B. Free radicals, antioxidants, and human disease: curiosity, cause or consequence. Lancet 344 : 721-724, 1994

6 - FREI B. Reactive oxygen species and antioxidant vitamins: mechanisms of action. Am J Med 97: 5S-13S, 1994. Suppl.

7 - SERHAN C et al. Phosphatidate and oxidized fatty acids are calcium ionophores. J Biol Chem 256: 2736-2741, 1981.

8 - HALLIWELL B et al. Free radicals, antioxidants and human disease: where are we now? J Lab Clin Med 119: 598-620, 1992.

9 - SIES H. Strategies of antioxidant defense. Eur J Biochem 215: 213-219, 1993.

10 - DUTHIE GG. Lipid peroxidation. Eur J Clin Nutr 47: 759-764, 1993.

11 - JACOB RA. The integrated antioxidant system. Nutr Res 15: 755-766, 1995.

12 - OLSON RE. Vitamin E and its relation to heart disease. Circulation 48: 179-184, 1973.

13 - BJORNEBOE GEA et al. Reduced hepatic $\alpha$-tocopherol content after long-term administration of ethanol to rats. Biochim Biophys Acta 918: 236-241, 1987.

14 - LIEBLER DC. The role of metabolism in the antioxidant function of vitamin E. Crit Rev Toxicol 23: 147-169, 1993.

15 - CHAN WKM \& DECKER EA. Endogenous skeletal muscle antioxidants. Crit Rev Food Sci Nutr 34: 403-426, 1994.

16 - MACHLIN LJ \& BENDICH A. Free radical tissue damage: protective role of antioxidant nutrients. FASEB J 1: 441-445, 1987.

17 - JORDÃO JR AA et al. Urinary excretion and plasma vitamin E levels in patients with AIDS. Nutrition 14: 423-426, 1998.

18 - Di MASCIO P et al. Antioxidant defense systems: the role of carotenoids, tocopherols and thiols. Am J Clin Nutr 53: 194S-200S, 1991.

19 - PACKER L. Protective role of vitamin E in biological systems. Am J Clin Nutr 53: 1050S-1055S, 1991. Suppl. 4

20 - STOCKER R et al. Ubiquiunol-10 protects human low density lipoproteinmore efficiently against lipid peroxidation than does alpha-tocopherol. Proc Natl Acad Sci (USA) 88: 1646-1650, 1991.
21 - MOORE ANJ \& INGOLD KU. $\alpha$-Tocoferyl quinone is converted into vitamin $E$ in man. Free Radic Biol Med 22: 931-934, 1997.

22 - KOHAR I et al. Is a $\alpha$-tocopherol a reservoir for $\alpha$-tocopheryl hidroquinone. Free Radic Biol Med 19: 197-207, 1995.

23 - BENDICH A \& MACHLIN LJ. Safety oral intake of Vitamin E. Am J Clin Nutr 48: 612-619, 1988.

24 - CORRIGAN Jr JJ. The effect of vitamin E on warfarin induced vitamin K deficiency. Ann N Y Acad Sci 292: 361-368, 1982.

25 - BRAY TM \& TAYLOR CG. Tissue glutathione, nutrition and oxidative stress. Can J Physiol Pharmacol 71: 746-751, 1993.

26 - MEISTER A. Glutathione metabolism. Methods Enzymol 251: 3-7, 1995.

27 - KRETZSCHMAR M. Regulation of hepatic glutathione metabolism and its role in hepatotoxicity. Exp Toxicol Pathol 48: 439-446, 1996.

28 - SHAN $X$ et al. Glutathione dependent protection against oxidative injury. Pharmacol Ther 44: 61-71, 1990.

29 - JONES DP et al. Impact of nutrients on cellular lipid peroxidation and antioxidant defense system. Fundam Appl Toxicol 26: 1-7, 1995.

30 - UHLIG S \& WENDEL A. The physiological consequences of glutathione variations. Life Sci 51: 1083-1094, 1992.

31 - LIEBER CS. Ethanol. metabolism, cirrhosis and alcoholism. Clin Chim Acta 257: 59-84, 1997.

32 - KITSON KE \& WEINER $\mathrm{H}$. Ethanol and acetaldehyde metabolism: past, present and future. Alcohol Clin Exp Res 20: 82A-92A, 1996.

33 - SONG BJ \& CEDERBAUM AI. Ethanol-inducible cytochrome P450 (CYP4502E1): biochemistry, molecular biology and clinical relevance: 1996 update. Alcohol Clin Exp Res 20: 138A-146A, 1996.

34 - ISHII H \& THURMAN RG. Oxidative stress in alcoholic liver injury. Alcohol Clin Exp Res 20: 162A-167A, 1996.

35 - POLI G. Liver damage due to free radicals. Br Med Bull 49: 604-620, 1993.

36 - DERR RF et al. Is ethanol per se hepatotoxic? J Hepatol 10: 381-386, 1990.

37 - VANNUCCHI H et al. Tryptophan metabolism in in alcoholic pellagra patients: measurement of urinary metabolites and histochemical studies of related muscle enzimes. Am J Clin Nutr 35: 1368-1374, 1982.

38 - VANNUCCHI H \& MORENO FS. Interaction of niacin and zinc metabolism in patients with alcoholic pellagra. Am J Clin Nutr 50: 364-369, 1989.

39 - VANNUCCHI $\mathrm{H}$ et al. Alcoolismo e nutrição: aspectos fisiopatológicos, clínicos e terapêuticos. Rev CEN 6: 13-20, 1982.

40 - VANNUCCHI $\mathrm{H}$ et al. Assessment of zinc nutritional status of pellagra patients. Alcohol Alcoh 30: 297-302, 1995. 
41 - VANNUCCHI H et al. Interaction among niacin, vitamin $\mathrm{B}_{6}$ and zinc in rats receiving ethanol. Int $\mathbf{J}$ Vitam Nutr Res 56: 355-362, 1986.

42 - VANNUCCHI $\mathrm{H}$ et al. Plasma amino acid patterns in alcoholic pellagra patients. Alcohol Alcoh 26: 431-436, 1991.

43 - VANNUCCHI $\mathrm{H}$ et al. Amino acid patterns in the plasma and ascitic fluid of cirrhotic patients. Braz $\mathbf{J}$ Med Biol Res 18: 465-470, 1985.

44 - MARCHINI JS et al. Protein requirements of a group of chronic alcoholics: efficiency of duodenal amino acid infusion. Nutr Res 8: 239-248, 1988.

45 - CUNHA DF \& VANNUCCHI H. Estudo do valor nutricional do leite de soja no tratamento de alcoólatras desnutridos. Rev Assoc Med Bras 37: 163-168, 1991.

46 - REID AMB \& SLATER TF. Some effects of ethanol in vivo and in vitro lipid peroxidation. Biochem Soc Trans 5: 1292-1294, 1977

47 - TORRIELLI MV et al. Ethanol-induced hepatotoxicity: experimental observations on the role of lipid peroxidation. $\mathbf{J}$ Pathol 126: 11-25, 1978.

48 - ALBANO E et al. Spin trapping studies on the free-radical products formend by metabolic activation of carbon tetrachloride in rat liver microssomal fractions isolated hepatocytes and in vivo in the rat. Biochem J 204: 593-603, 1982.

49 - MÜLLER A \& SIES H. Alcohol, aldehydes and lipid peroxidation: Current notions. Alcohol Alcoh 1: 67-74, 1987. Suppl.

50 - REINKE LA et al. Reactive free radical generation in vivo in heart and liver of ethanol-fed rats: Correlations with radical formation in vitro. Proc Natl Acad Sci (USA) 84: 9223-9227, 1987.

51 - NORDMANN R et al. Implication of free radical mechanisms in ethanol- induced cellular injury . Free Radic Biol Med 12: 219-240, 1992.

52 - EKSTRÖM G \& INGELMAN-SUNDBERG M. Rat liver microssomal NADPH-supported oxidase activity and lipid peroxidation dependent on ethanol inducible cytocrome P450 (P450 IIE1). Biochem Pharmacol 38: 1313-1319, 1989.

53 - THURMAN R.G. Induction of hepatic microssomal NADPH-dependent production of hydrogen peroxide by chronic prior treatment with ethanol. Mol Pharmacol 9: 670-675, 1973.

54 - DICKER E. \& CEDERBAUM AI. HydroxyL radical generation by microssomes after chronic ethanol comsumption. Alcoh Clin Exp Res 11: 309-314, 1987

55 - JOHANSSON I et al. Ethanol, fasting and acetone-inducible cytocrome P-450 in rat liver: Regulation and charactheristics of enzimes belonging to IIB and IIE gene subfamilies. Biochemistry 27:1925-1934, 1988.

56 - KOOP DR et al. Immunochemical evidence for induction of the alcohol-oxidizing cytochrome P-450 of rabbit liver microsomes by diverse agents: Ethanol, imidazole, trichloroethylene, acetone, pyrazole and isoniazid. Proc Natl Acad Sci (USA) 82: 4065-4069, 1985.
57 - SLATER TF et al. Changes in liver nucleotide concentrations in experimental liver injury. 2. Acute ethanol poisoning. Biochem J 93: 267-270, 1964

58 - SINACEUR $J$ et al. Superoxide formation in liver mithocondria during ethanol intoxication: Possible role in alcohol hepetotoxicity. In: POLI G et al., eds. Free Radicals in liver injury. Oxford, IRL Press, p. 175-177, 1985

59 - PORTA EA \& GOMEZ-DUMM CLA. A new experimental approach in the study of chronic alcoholism. Lab Invest 18: 352-364, 1968.

60 - SADRZADEH SMH \& NANJI AA. Detection of lipid peroxidation after acute ethanol administration is dependent of time of sampling. Int J Vitam Nutr Res 64: 157-158, 1994.

61 - COUDRAY C et al. Blood and liver peroxide status after chronic ethanol administration in rats. Clin Chim Acta 219: 35-45, 1993.

62 - TYOPPONEN JT \& LINDROS KO. Combined vitamin E deficiency and ethanol pretreatment: liver glutathione and enzime changes. Int J Nutr Res 56: 241-245, 1986.

63 - TANAKA T et al. Effect of vitamin E deficiency on inhibition of liver regeneration by long term administration of alcohol. Alcohol Clin Exp Res 20: 47-50, 1996.

64 - IWASAKI $M$ et al. Effects of vitamin E deficiency on hepatic microssomal cytocrome P450 and phase II enzymes in male and female rats. Int J Vitam Nutr Res 64: 109-112, 1994.

65 - HANNAH JS \& SOERES JH. The effects of vitamin E on the ethanol metabolizing liver in the rat. Nutr Rep Int 19: 733-744, 1979

66 - WANG S-T et al. Vitamin E protection of cell morphology and protein thiols in rat hepatocytes treated with tert-butyl hydroperoxide. Toxicol Lett 89: 91-98, 1996.

67 - SADRZADEH SMH et al. Effect of chronic ethanol feeding on plasma and liver $\alpha$-and- $\gamma$-tocopherol levels in normal and vitamin E deficient rats. Biochem Pharmacol 47: 2005-2010, 1994.

68 - LIEBER CS. The influence of alcohol on nutritional status. Nutr Rev 46: 241-253, 1988.

69 - GOSSUM AV et al. Deficiency in antioxidant factors in patients with alcohol-related chronic pancreatitis. Dig Dis Sci 41: 1225-1231, 1996.

70 - ALTOMARE E et al. Hepatic glutathione content in patients with alcoholic and non-alcoholic liver diseases. Life Sci 43: 991-998, 1988

71 - MAELLARO E et al. Lipid peroxidation and antioxidant systems in the liver injury produced by glutathione depleting agents. Biochem Pharmacol 39: 1513-1521, 1990.

72 - PASCOE GA et al. Vitamin E protection against chemicalinduced cell injury. Arch Biochem Biophys 256: 150-158, 1987.

73 - CALLANS DJ et al. Effects of ethanol feeding and withdrawal on plasma glutathione elimination in the rat. Hepatology 7 : 496-501, 1987. 
74 - BOYER CS \& PETERSEN DR. Potentiation of cocainemediated hepatotoxicity by acute and chronic ethanol. Alcoh Clin Exp Res 14: 28-31, 1990.

75 - HASSING JM et al. Hepatic glutathione in D-penicillaminefed ethanol dependent rats. Res Commun Chem Pathol Pharmacol 25: 389-394, 1979.

76 - FERNANDEZ V \& VIDELA LA. Effect of acute and chronic ethanol ingestion on the content of reduced glutathione of various tissues of the rat. Experientia 37: 392-394, 1981.

77 - VINA J et al. Effect of ethanol on glutathione concentrations in isolated hepatocytes. Biochem J 188: 549-552, 1980.

78 - VIDELA LA et al. Liver lipoperoxidative pressure and glutathione status following acetaldehyde and aliphatic alcohols pretreatment in rats. Biochem Biophys Res Commun 104: 965-970, 1982.

79 - SARDAR $S$ et al. Comparative effectiveness of vitamin $D_{3}$ and dietary vitamin $E$ on peroxidation of lipids and enzimes of the hepatic antioxidant system in Sprague-Dawley rats. Int J Vitam Nutr Res 66: 39-45, 1996.

80 - KAWASE T et al. Lipid peroxidation and antioxidant defense system in rat liver after chronic ethanol feeding. Hepatology 10: 815-821, 1989.

81 - SADRZADEH SMH et al. High dose vitamin E supplementation has no effect on ethanol induced pathological liver injury. J Pharmacol Exp Ther 273: 455-460, 1995.
82 - MacDONALD CM. The effects of ethanol on hepatic lipid peroxidation and on the activities of glutathione reductase and peroxidase. FEBS Lett 35: 227-230, 1973.

83 - CALABRESE $\mathrm{V}$ et al. Stress proteins and SH-groups in oxidant-induced cell damage after acute ethanol administration in rat. Free Radic Biol Med 20:391-397, 1996.

84 - AMERICAN DIETETIC ASSOCIATION. Position of the American Dietetic Association: vitamin and mineral supplementation. J Am Diet Assoc 96: 73-77, 1996.

85 - LAUREAUX C et al. a-Tocoferol enrichement of high-density lipoproteins: stabilization of hydroperoxides produced during cooper oxidation. Free Radic Biol Med 22: 185-194, 1997.

86 - CAO G \& CUTLER RG. High concentrations of antioxidants may not improve defense against oxidative stress. Arch Gerontol Geriatr 17: 189-201, 1993.

87 - NEUZIL J et al. Requirement for promotion, or inhibition by a-tocoferol of radical induced initiation of plasma lipoprotein lipid peroxidation. Free Radic Biol Med 22: 57-71, 1997.

88 - MAZA MP et al. Effects of long-term vitamin E supplementation in alcoholic cirrhotics. J Am Coll Nutr 14: 192-196, 1995.

Recebido para publicação em 12/06/98.

Aprovado para publicação em 01/09/98 